\title{
Towards the prevention of acute lung injury: a population based cohort study protocol
}

\author{
Sweta J Thakur,, Cesar A Trillo-Alvarez, Michael M Malinchoc, Rahul Kashyap, Lokendra Thakur, Adil Ahmed, \\ Martin K Reriani, Rodrigo Cartin-Ceba, Jeff A Sloan, Ognjen Gajic
}

\begin{abstract}
Background: Acute lung injury (ALI) is an example of a critical care syndrome with limited treatment options once the condition is fully established. Despite improved understanding of pathophysiology of ALI, the clinical impact has been limited to improvements in supportive treatment. On the other hand, little has been done on the prevention of ALI. Olmsted County, MN, geographically isolated from other urban areas offers the opportunity to study clinical pathogenesis of ALI in a search for potential prevention targets.

Methods/Design: In this population-based observational cohort study, the investigators identify patients at high risk of ALI using the prediction model applied within the first six hours of hospital admission. Using a validated system-wide electronic surveillance, Olmsted County patients at risk are followed until ALI, death or hospital discharge. Detailed in-hospital (second hit) exposures and meaningful short and long term outcomes (qualityadjusted survival) are compared between ALI cases and high risk controls matched by age, gender and probability of developing ALI. Time sensitive biospecimens are collected for collaborative research studies. Nested case control comparison of 500 patients who developed ALI with 500 matched controls will provide an adequate power to determine significant differences in common hospital exposures and outcomes between the two groups.
\end{abstract}

Discussion: This population-based observational cohort study will identify patients at high risk early in the course of disease, the burden of ALI in the community, and the potential targets for future prevention trials.

\section{Background}

Acute lung injury (ALI) and its more severe form Acute respiratory distress syndrome (ARDS) are common and devastating complications after acute illness or injury with high morbidity and mortality, long term decrease in quality of life, and enormous costs related to intensive care and rehabilitation [1]. ALI is an example of a critical care syndrome with limited treatment options once the condition is fully established. Despite improved understanding of the pathophysiology of ALI, the clinical impact has been limited to improvements in supportive treatment $[2,3]$. Surprisingly little research has been done on the prevention of ALI. Preclinical studies support a "two hit" model of development of ALI whereby different exposures modify the expression of ALI in susceptible host [4]. Preliminary data suggest that ALI is

\footnotetext{
* Correspondence: sweta2152002@yahoo.com

Multidisciplinary Epidemiology and Translational Research in Intensive Care (M.E.T.R.I.C.), Division of Pulmonary and Critical Care Medicine, Mayo Clinic
} College of Medicine, Rochester, Minnesota, USA rarely present at the time of hospital admission but develops over a period of hours to days in subsets of patients with predisposing conditions such as pneumonia, sepsis, trauma, shock and corresponding medical and surgical interventions [5-12]. To this extent, ALI may be viewed as potentially preventable hospital complication similar to stress ulcer bleeding, venous thromboembolism or nosocomial infections. Previous clinical studies enrolled patients after ICU admission, often with already established ALI, beyond the window of meaningful mechanistic studies and potential prevention strategies [13-15]. Not surprisingly, many treatments targeting the mechanisms identified in preclinical studies have failed to improve patient outcomes despite compelling preclinical data [16-19]. It is likely that, inadequate and delayed recognition of patients at risk and the subsequent development of the full blown syndrome have obscured the therapeutic window. ALI usually develops during the first hours of ICU admission, and often is the very reason for ICU admission. On the other hand, the majority of 
patients with predisposing conditions never develop ALI and they may never been admitted to the ICU making the enrollment of unselected patients into ALI prevention studies neither feasible nor efficient $[12,10]$. A meaningful approach to ALI prevention therefore ought to be based on identifying patients at risk earlier than what is currently done (at the time of hospital admission, rather than ICU admission, Figure 1) [10].

\section{Methods/Design}

In this population based cohort study the investigators will identify patients at risk early in the course of the disease and before the development of ALI (at the time of hospital admission). Detailed in-hospital exposures, short and long term outcomes will be compared between patients at high risk who do and do not develop ALI. (Figure 2)

\section{Inclusion Criteria}

Olmsted County residents more than 18 years of age admitted to the two Mayo Clinic Rochester hospitals with one or more of the ALI predisposing conditions (sepsis, pneumonia, aspiration, pancreatitis, shock, high risk trauma, and high risk surgery). (Table 1) Exclusion criteria are listed in Table 2. Institutional review board has approved the study protocol.

\section{System-wide electronic surveillance}

Electronic medical records (EMR) facilitate early recognition of specific study criteria using Boolean combinations of clinical variables and natural language processing. In this study we are planning to use a customized, integrative relational research database that contains a near-real time (15 minutes delay) copy of electronic medical records (ICU DataMart). To identify Olmsted County residents at risk admitted to the two Mayo Clinic hospitals, ICU DataMart uses 9-digit ZIP code and a specific nursing unit codes and generates email and/or pager alert within 15 minutes from the time the patient is assigned a bed in the receiving unit. Patients admitted for labor and delivery, specific procedures (cardiac catheterization), cardiac telemetry, coronary care unit, low risk elective surgeries and children are excluded from the alerts. Screening for ALI development is performed by previously validated ARDS "sniffer" $[20,21]$. The electronic alert is triggered by the following combination of observations: 1) qualifying arterial blood gas analysis: the ratio of partial pressure of oxygen to inspired oxygen concentration $\left(\mathrm{PaO}_{2} / \mathrm{FIO}_{2}\right)$ $<300$ and 2) qualifying chest radiograph report: free text Boolean query containing trigger words: ("bilateral" AND "infiltrate") OR "edema" The ARDS sniffer demonstrated excellent negative predictive value $(0.99$, $95 \%$ CI 0.98 to 1.00 ) [20]. ARDS-sniffer has been continuously running since December of 2005 allowing for prospective identification of ALI cases. Access to the database is accomplished through password protected open database connectivity (ODBC) using JMP and SAS statistical software (SAS Institute Inc., Cary, NC, USA).

\section{Early identification of patients at risk of ALI (lung injury prediction score - LIPS)}

To facilitate enrollment of patients into mechanistic and outcome studies as well as future ALI prevention trials, we have recently developed an ALI prediction model (Lung Injury Prediction Score: LIPS, Table 1) [22]. LIPS

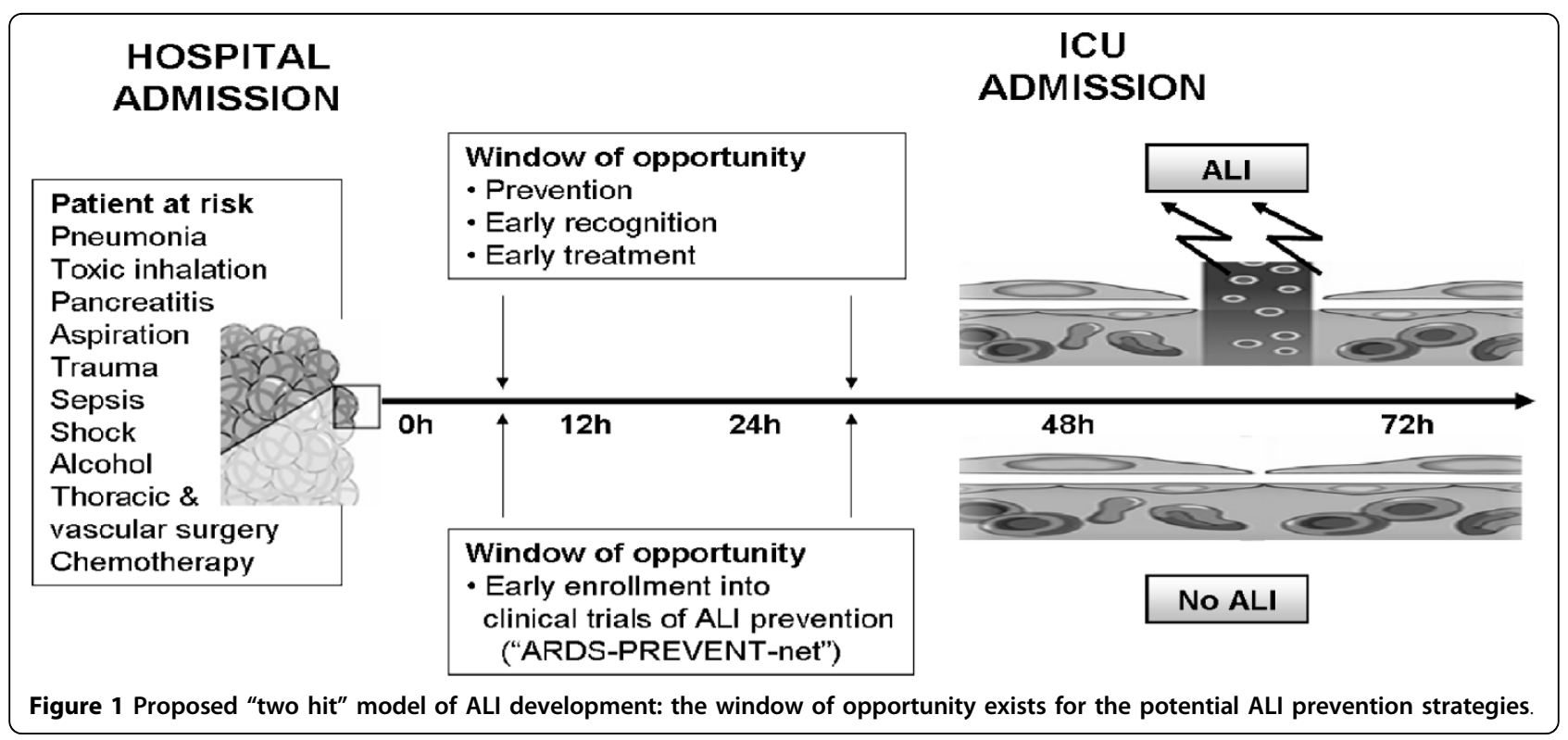




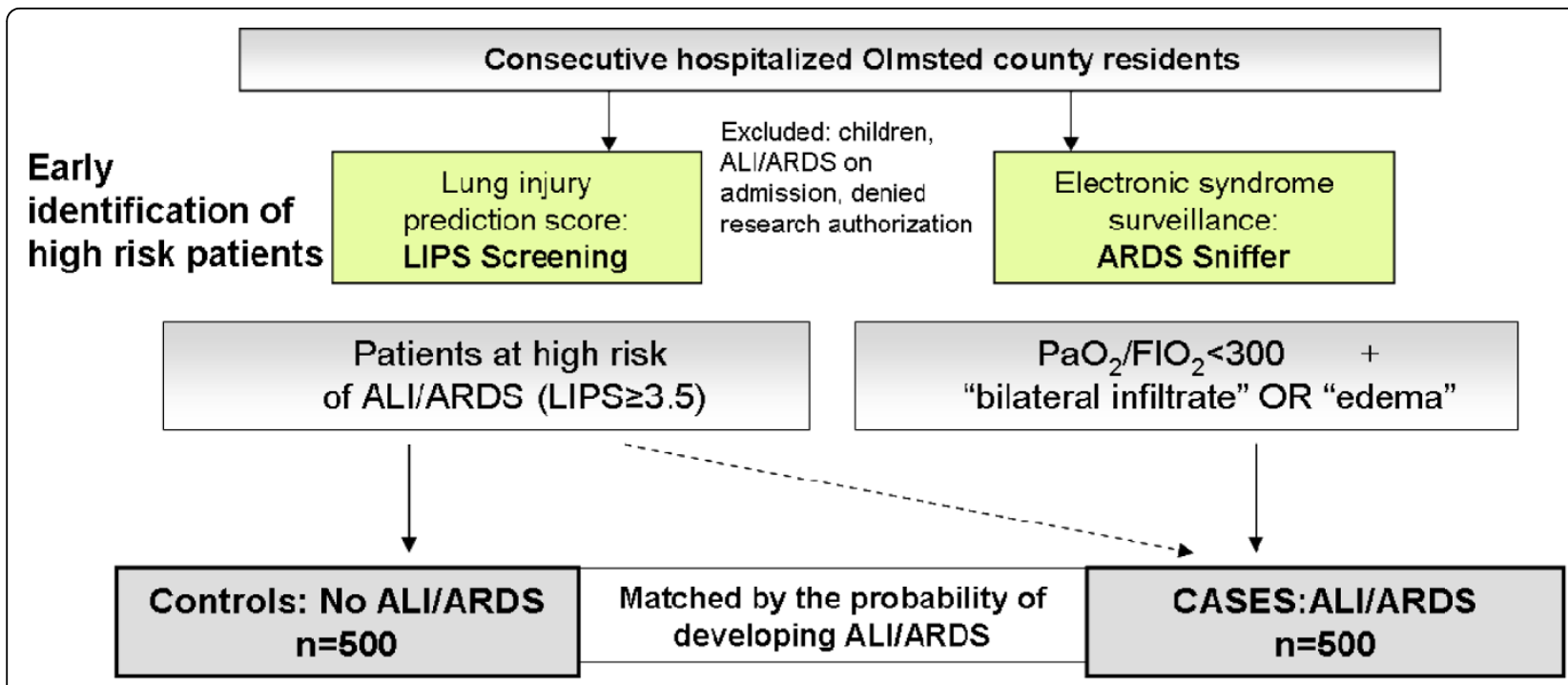

\section{In hospital \\ exposures}

High resolution monitoring of nursing \& physsician interventions

\section{Relevant outcomes}

Biospecimen collection for collaborative studies

Six months unadjusted and guality adjusted survival, hospital \& intensive care unit length of stay QOL neuromuscular cognitive \& psychologic surveys

Figure 2 Outline of the study design.

Table 1 Predisposing conditions and modifiers available before or within six hours after hospital admission used to calculate the lung injury prediction score (LIPS): [22].

\begin{tabular}{ll}
\hline Risk factors & Measurement \\
\hline Pneumonia & Yes/No \\
Sepsis & Yes/No, severe \\
Pancreatitis & Yes/No \\
Aspiration (pre-admission) & Yes/No \\
High risk trauma & Lung contusion, smoke inhalation, near-de bone, brain injury \\
& $\begin{array}{l}\text { Aortic vascular, spine, thoracic, acute abd } \\
\text { emergency }\end{array}$ \\
High risk surgery & Yes/No, amount (\# of drinks a week) \\
Risk Modifiers & Never/former/current/\# of pack-years \\
Alcohol use & Yes/No \\
Smoking & Yes/No \\
Diabetes mellitus* & Yes/No \\
Interstitial lung disease & \\
Chemotherapy & \\
Tachypnea (respiratory rate>30), & \\
High inspired oxygen \\
concentration (FlO2>0.35) \\
Hypoalbuminemia
\end{tabular}

Definition

Consensus Conference [24]

SCCM-ACCP definition [25]

Practice guidelines in acute pancreatitis [26]

Inhalation of food or gastric contents [27]

From Derdak [28]

From Arozullah et al $[29,30]$

More than 2 drinks per day or a history of alcohol-related illness or admission [31,32]

Substance Abuse and Mental Health

Diabetes care 2009 [33]

ATS-ERS Consensus classification of IIP [34]

Custom, cancer chemotherapeutic drugs during the 6 months prior to hospitalization

Based on the worst value during the first 6 hours

Based on the worst value during the first 6 hours

Serum albumin $<3.5 \mathrm{~g} / \mathrm{dL}$, the absence of measurement considered normal 
Table 2 Exclusion criteria.

\begin{tabular}{|c|c|}
\hline Exclusion Criteria & Justification \\
\hline $\begin{array}{l}\text { Acute lung injury or pulmonary } \\
\text { edema already present at the time of } \\
\text { hospital admission }\end{array}$ & $\begin{array}{l}\text { Unable to assess for } \\
\text { development of outcome of } \\
\text { interest }\end{array}$ \\
\hline $\begin{array}{l}\text { Admitted for comfort or hospice care } \\
\text { only }\end{array}$ & $\begin{array}{l}\text { Missing predictor and outcome } \\
\text { variables }\end{array}$ \\
\hline $\begin{array}{l}\text { Denied the use of medical records for } \\
\text { research }(\sim 5 \%)\end{array}$ & Self explanatory \\
\hline $\begin{array}{l}\text { Patients admitted for cardiac } \\
\text { telemetry, coronary care unit, low risk } \\
\text { elective surgeries, labor and delivery }\end{array}$ & $\begin{array}{l}\text { Very low risk of outcome of } \\
\text { interest }\end{array}$ \\
\hline Children & $\begin{array}{l}\text { Different risk factors and } \\
\text { outcome }\end{array}$ \\
\hline Hospital readmission & Complexity of analysis \\
\hline Hospital transfer & $\begin{array}{l}\text { Exposure to health care } \\
\text { interventions }\end{array}$ \\
\hline
\end{tabular}

incorporates demographic, and clinical characteristics at the time of, and before, hospital admission. Risk factors for ALI that were identified in at least two previous studies were used in model development. LIPS points were determined based on parameter estimates from the logistic regression model, taking into consideration results from our previous studies. The model accurately discriminated between the patients who did and did not develop ALI with an area under the receiver operating curve of 0.85 (95\% CI 0.80 to 0.89 ) [22].

Twice daily (7 AM and 5 PM, Monday-Saturday) trained study coordinators review syndrome surveillance alerts of new Olmsted County admissions and apply LIPS points to patients who fulfill the inclusion criteria according to LIPS score sheet. ODBC MS Access database tool is used for the collection of individual patient data in a systematic way. The database automatically links MS Access to ICU Datamart server and imports new patients from ICU Datamart to the LIPS database. The database also links automatically to the IRB research authorization web site identifying the patients that have approved the use of their medical data for research.

\section{Validation of the primary outcome (ALI)}

Primary outcome is the development of ALI at any time during the hospital stay. Trained investigators review each ARDS sniffer alert (see above) and confirm the presence or absence of ALI according to the standard definition based on the American-European consensus conference [21]. The absence of left atrial hypertension as the principal explanation for pulmonary edema is confirmed by integrated clinical evaluation based on the following:

- Echocardiography $\left(\mathrm{E} / \mathrm{E}^{\prime}<15, \mathrm{EF}>45\right)$

- Pulmonary artery occlusion pressure (PAOP) $\leq 18$ cm $\mathrm{H} 2 \mathrm{O}$
- Central venous pressure $(\mathrm{CVP}<15) \mathrm{cm} \mathrm{H} 2 \mathrm{O}$ (higher cutoff in pulmonary hypertension)

- History of congestive heart failure/cardiogenic pulmonary edema

- Brain natriuretic peptide (BNP) $<250 \mathrm{pg} / \mathrm{mL}$ (higher cutoff in renal failure)

- Response to preload reduction: brisk (hours) response to diuretics and/or positive pressure ventilation favors hydrostatic edema

This process yielded good interobserver agreement for differentiation between ALI and hydrostatic edema (Kappa value 0.83 in the most recent retrospective Olmsted county study) [10].

\section{Identification of in-hospital exposures}

To identify candidate interventions for ALI prevention, we are planning to identify hospital acquired ( $2^{\text {nd }}$ hit) environmental exposures that may modify the risk of ALI and its consequences in high risk subgroups of patients residing in the Olmsted County community identified by the LIPS model. Timing and intensity of environmental exposures (Table 3) will be determined by the review of monitoring logs, nursing and physician interventions in the EMR by trained study coordinators blinded to ALI status. Only the exposures occurring before development of the ALI in cases and during the corresponding period of time in controls will be analyzed as modifiers of ALI development.

\section{Bio specimen collection and storage for collaborative genomic and biomarker studies}

Having identified both a robust phenotype and a detailed account of potentially important environmental exposures we will collect time sensitive peripheral blood samples for collaborative genome-wide association and plasma biomarker studies. Waste blood samples collected for routine clinical care will be collected at baseline (hospital admission), after 24 and 48 hours, and on the day of development of ALI (if outside these 3 time points).

\section{Attributable burden of ALI}

To prioritize future ALI prevention strategies, we are planning to determine the attributable burden of ALI in the Olmsted County community by quantifying patientcentered outcomes attributable to this condition. The essential patient-centered outcomes (unadjusted and quality-adjusted survival, neurocognitive, neuropsychologic and neuromuscular complications, functional outcome, and quality of life) will be compared between patients who do and do not develop ALI. The instruments we have chosen to evaluate our patients are listed in Table 4. These instruments were selected to assess 
Table 3 Hospital (second hit) exposures that may modify the development of ALI in high risk patients.

\begin{tabular}{|c|c|c|}
\hline & Variable & Measurements \\
\hline \multicolumn{3}{|c|}{ A. Exposures associated with development of ALI in preliminary studies } \\
\hline \multirow{2}{*}{$\begin{array}{l}\text { Treatment of } \\
\text { infection }\end{array}$} & Antibiotics & Time to administration of adequate antibiotics \\
\hline & Source control & List source, time to source control \\
\hline Shock resuscitation & Early goal directed resuscitation & Time to completion of goal directed resuscitation \\
\hline Blood transfusion & Red blood cells, fresh frozen plasma, platelets & $\begin{array}{l}\text { Number of units, donor gender and pregnancies, storage age of red cells } \\
\text { and platelets }\end{array}$ \\
\hline \multirow[t]{5}{*}{$\begin{array}{l}\text { Respiratory } \\
\text { support }\end{array}$} & Inspired oxygen concentration $\left(\mathrm{FIO}_{2}\right)$ & $\begin{array}{l}\text { AUC, mean, median and maximum value during the exposure time of } \\
\text { interest }\end{array}$ \\
\hline & Ventilator tidal volumes (mL/kg predicted weight) & $\begin{array}{l}\text { AUC, mean, median and maximum value during the exposure time of } \\
\text { interest }\end{array}$ \\
\hline & Peak and plateau airway pressures $\left(\mathrm{cm} \mathrm{H}_{2} \mathrm{O}\right)$ & $\begin{array}{l}\text { AUC, mean, median and maximum value during the exposure time of } \\
\text { interest }\end{array}$ \\
\hline & PEEP $\left(\mathrm{cm} \mathrm{H}_{2} \mathrm{O}\right)$ & 5-10 (reference), $<5,>10 \mathrm{~cm} \mathrm{H}_{2} \mathrm{O}$ \\
\hline & Respiratory rate & $\begin{array}{l}\text { AUC, mean, median and maximum value during the exposure time of } \\
\text { interest }\end{array}$ \\
\hline \multirow[t]{2}{*}{ Medications } & Amiodarone & Cumulative dose during the exposure time of interest \\
\hline & Chemotherapy & Cumulative dose during the exposure time of interest \\
\hline \multirow{2}{*}{$\begin{array}{l}\text { Other } \\
\text { complications }\end{array}$} & Aspiration (in hospital) & Inhalation of food or gastric contents \\
\hline & Medical or surgical misadventures & List complication (ICD-9 code E870-E879.9) \\
\hline \multicolumn{3}{|c|}{ B. Additional biologically plausible hospital exposures - exploratory analysis } \\
\hline Mechanism & Variable & Measurements \\
\hline \multirow[t]{4}{*}{ Inflammation } & Corticosteroids, inhaled and systemic & Cumulative dose during the exposure time \\
\hline & Statins & Cumulative dose during the exposure time \\
\hline & Insulin & Cumulative dose during the exposure time \\
\hline & ACE inhibitor & Cumulative dose during the exposure time \\
\hline Oxidative stress & $\begin{array}{l}\text { Antioxidants: } N \text {-Acetylcysteine, vitamin } C, \text { Vit } E, \Omega 3 \\
\text { fatty acids }\end{array}$ & Cumulative dose during the exposure time \\
\hline \multirow[t]{2}{*}{ Coagulation } & Anticoagulants (heparin, coumadin) & Cumulative dose during the exposure time \\
\hline & Antiplatelet agents (aspirin, clopidogrel) & Cumulative dose during the exposure time \\
\hline \multirow[t]{6}{*}{ Aspiration } & Head of the bed position & Above horizontal \\
\hline & Gastric tube feeding & Cumulative dose during the exposure time \\
\hline & Sedative agents & Cumulative dose during the exposure time \\
\hline & Narcotics & Cumulative dose during the exposure time \\
\hline & Antipsychotics & Cumulative dose during the exposure time \\
\hline & Gastric acid agents ( $\mathrm{H}_{2}$ blockers, PPIs) & Cumulative dose during the exposure time \\
\hline \multirow[t]{4}{*}{ Metabolic } & IV fluid (saline, Ringer, albumin) & Cumulative dose during the exposure time \\
\hline & Furosemide & Cumulative dose during the exposure time \\
\hline & Beta agonists, inhaled and systemic & Cumulative dose during the exposure time \\
\hline & $\begin{array}{l}\text { Laboratory findings: albumin, } \mathrm{pH} \text {, glucose, } \\
\text { osmolarity }\end{array}$ & The worst value during the exposure time of interest \\
\hline
\end{tabular}

AUC - area under the curve, PEEP - positive end expiratory pressure

PPI - proton pump inhibitor

the key domains of patient centered outcomes without jeopardizing the ability and willingness of the patients to provide data. Specifically these instruments will give a general measure of Quality of life (QOL) (SF12), along with measures of physical, cognitive and psychological functioning and would provide a comprehensive picture of our patients' experience. Baseline (premorbid) functional status and QOL will be determined by in-hospital retrospective survey of the patients or their surrogates. After obtaining informed consent trained study coordinators establish if the patient is competent to complete the entire questionnaire by administering the mini mental test. If patient is deemed incompetent or too ill to complete the survey a surrogate will be identified to help fill the questionnaires. Follow-up contact information will be obtained and the patients or their surrogate 
Table 4 Patient-reported outcome assessment.

\begin{tabular}{|c|c|c|}
\hline Variable & Instrument & Time(s) of assessment \\
\hline Quality of life & SF-12 health survey & $\begin{array}{l}\text { 1. In hospital retrospective assessment of pre morbid QOL } \\
\text { 2. } 6 \text { month follow up }\end{array}$ \\
\hline Physical function & Barthel Index & $\begin{array}{l}\text { 1. In hospital retrospective assessment of pre morbid } \mathrm{QOL} \\
\text { 2. } 6 \text { month follow up }\end{array}$ \\
\hline Neuromuscular complications & Overall neuropathy limitations scale & $\begin{array}{l}\text { 1. In hospital retrospective assessment of pre morbid } \mathrm{QOL} \\
\text { 2. } 6 \text { month follow up }\end{array}$ \\
\hline Neurocognitive complications & Folstein mini-mental status scale & $\begin{array}{l}\text { 1. In hospital retrospective assessment of pre morbid } \mathrm{QOL} \\
\text { 2. } 6 \text { month follow up }\end{array}$ \\
\hline $\begin{array}{l}\text { Neuropsychological } \\
\text { complications }\end{array}$ & $\begin{array}{l}\text { 1. Post-Traumatic Stress Syndrome (PTSS-10) (only at } 6 \\
\text { months) } \\
\text { 2. Yale depression scale }\end{array}$ & $\begin{array}{l}\text { 1. In hospital retrospective assessment of pre morbid } \mathrm{QOL} \\
\text { 2. } 6 \text { month follow up }\end{array}$ \\
\hline
\end{tabular}

who successfully complete the baseline survey will be contacted by telephone six month after index hospitalization.

\section{Strategies for subject retention}

We selected survey instruments to minimize respondent burden. In preliminary testing, respondents completed the battery of tests in less than 15 minutes. At baseline the research assistant administer the questionnaire with the use of visual aids to help with answering the questions. When obtaining the consent, patients will be informed of the follow up survey and the same research assistant will contact the patients at six months. This will help in establishing a rapport and increasing the response rate at follow-up. The average retention rate for the surveys conducted by the QOL research team at our institution is in excess of $80 \%$.

\section{Quality control and data management}

LIPS study collects a large number of data regarding patient exposures and outcomes. To reduce measurement error, a comprehensive data quality assurance program will be employed. Data will be maintained on a secure server with nightly back up. Single Mayo logon LAN ID (local area network identification) provides access to the data to authorized individuals. Electronic range checks and validation rules will eliminate erroneous data entry and artifacts in numeric values. As an independent quality control measure periodic audits of the database will be performed. Routine descriptive statistics will be obtained at regular intervals to assure completeness of data collection.

\section{Statistical Analysis}

An estimate for the probability of ALI development will be calculated for each patient based on the LIPS model. Because of subjective nature of clinical definitions used to identify the outcome of our study, it is necessary to assess interobserver variability. Interobserver agreement for ALI development will be assessed by calculating the
Kappa statistic, using a threshold of 0.6 as an indication of acceptable interobserver agreement.

The calibration and discrimination of model will be assessed using the Hosmer-Lemeshow goodness-of-fit test and the receiver operating characteristic curve, respectively. An area under the ROC curve greater than $80 \%$ will be considered to be the evidence of good model discrimination. Using a LIPS cutpoint of 3.5 or more identified in the preliminary data, the comparison of the model prediction versus the actual event observed will be summarized by a simple 2 by 2 table reporting ALI propensity versus ALI development. Summary measures, based on the 2 by 2 table, will be reported: sensitivity, specificity, positive predictive value, negative predictive value, positive and negative likelihood ratios along with their 95\% confidence intervals.

In a matched case-control design the associations suggested by preliminary clinical studies (Table 3) will be compared between ALI cases and high risk controls propensity matched by age, gender and the probability of ALI development at the time of hospital admission (LIPS, see above). Subpopulation analyses will be performed to determine what hospital exposures are associated with ALI in low/moderate ALI risk patients and what hospital exposures factors are associated with no ALI development in high ALI risk patients. The primary statistical endpoint is the development of ALI at any time during hospital stay. The matching is based on ALI risk at admission and the exposure period at risk. For example, if a hospitalized patient, who has an estimated propensity for developing ALI of $20 \%$ actually develops ALI 10 hours after hospital admission the exposures in matched control patient is only measured during the initial 10 hours after hospital admission. Paired statistics will be used for group comparisons. A conditional logistic regression model will be built in the case of baseline imbalances.

The statistical endpoints for determining attributable burden of ALI development in patients at risk are unadjusted and quality adjusted survival after hospital admission. All patients will be followed until death or 
study conclusion, and patients who survive will be censored at the last date known to be alive. In addition, we will assess which hospital exposures, impact the long-term survival and quality-adjusted survival in both ALI patients and high risk controls. We will use Kaplan-Mayer survival curves to depict survival differences in these subgroups. In order to understand the impact of ALI on quality of life, we will compare the 1 quality of life measures between the ALI patients and controls, taking into account the correlations between serial (baseline and follow up) QOL measurements. We will carry out quality-adjusted life years (QALY) analyses to incorporate the QOL-related health state utility variables into the survival analysis. We will combine survival and quality of life using the time spent in specific "health state" (ventilator, ICU, hospital, nursing home, home) to describe the quality adjusted survival of ALI patients according to the following formula:

$\mathrm{QALY}=\Sigma \mathrm{i}($ utility of health state $\mathrm{i}) *($ time patient spends in health state $\mathrm{i})$

We expect that missing data will be minimized due to the error checking capability of our data entry system. We will handle missing data in a number of ways including complete case analysis and imputation via nearest neighbor, mean value, last value, and zero value carried forward approaches. Multiple approaches are used so that the sensitivity of results to alteration in imputational assumptions may be assessed.

\section{Sample size considerations}

Planned enrollment of 500 ALI cases guarantee an adequate sample size for LIPS validation. If we have 500 ALI cases and $80 \%$ score above the threshold for the ALI model (sensitivity) then our precision will be .02 and the $95 \%$ CI would 0.78 to 0.82 .
A comparison of 500 ALI cases with 500 propensity matched high risk controls will allow us to determine moderately high associations (odds ratio $>2.0$ ) between common in-hospital exposures (prevalence $>5 \%$, i.e. variability in fluid management, transfusion, antibiotics, FIO2, mechanical ventilation) and ALI development (Figure 3). We will be able to identify only strong associations for less common in-hospital exposures $(<5 \%)$.

Assuming a median survival of around 2 years in control population and ALI increases the risk of death by about 1.25 , then the study has $80 \%$ power to reject the null hypothesis of equal survival of controls and ALI patients. A target of 100 ALI survivors and 100 controls assuming a standard deviation of the health related quality of life score among ICU patients of 10 units, the study has $80 \%$ power to detect a difference in self reported quality of life of 4.0 units or greater.

\section{Discussion}

The LIPS study is a population based observational cohort study that aims to identify patients at high risk of developing ALI early in the course of illness (at the time of hospital admission), and compare the in-hospital (second hit) exposures and outcomes of patients at high risk who do and do not develop ALI. Analysis and comparison of exposures and outcomes between patients at high risk identified before ALI development is essential to understand clinical pathogenesis of ALI and design effective prevention strategies. By determining not only candidate interventions, but also the attributable burden of ALI, it will allow the prioritization of preventive strategies and future clinical trials.

Olmsted County offers a unique opportunity to study potential ALI prevention targets in a geographically defined population because all the critically ill patients from the county are admitted to Mayo Clinic hospitals.

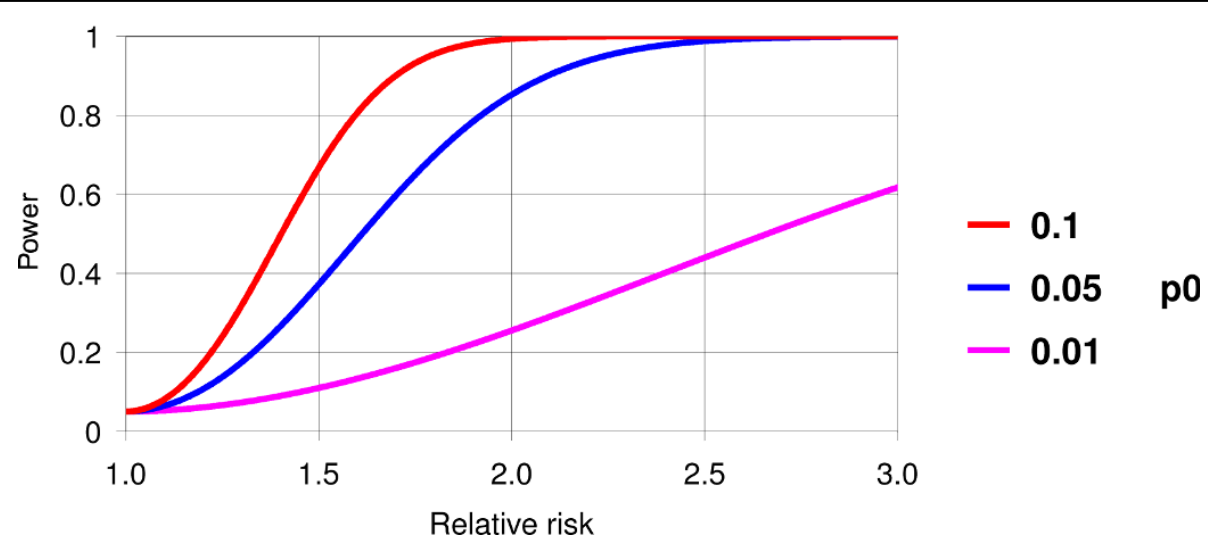

Figure 3 Power for a matched case control study of $500 \mathrm{ALI}$ patients matched to $\mathbf{5 0 0}$ controls where the risk factor occurs at $10 \%$, $\mathbf{5 \%}$, or $\mathbf{1 \%}$ prevalence in the controls and the false positive rate is $\mathbf{0 . 0 5}$. As depicted, if $5 \%$ of the controls experience delayed fluid resuscitation which increases the risk of ALI by 2 fold, then the study has about $82 \%$ power to reject the null hypothesis. 
The use of population based sample eliminates the referral bias common in clinical studies performed at tertiary care institutions [23]. As a part of study design we have developed a near real time access to pertinent data in electronic medical records to identify patients from the community with or at high risk of ALI. The electronic infrastructure will greatly facilitate to conduct this population based study by minimizing study coordinator time necessary to screen large number of patients. Time-sensitive biospecimen collection in a population of patients with strictly defined phenotype and detailed capture of environmental exposures will allow for the development of important biospecimen repository for future collaborations in Genome Wide Association and plasma biomarker studies.

The principal limitation of our study is imposed by the broad nature and definition of the primary outcome of interest, ALI [21]. The exclusion of left atrial hypertension poses a particular challenge in the clinical assessment of ALI. In addition to using a standardized definition and extensive training of study personnel, all ALI cases will be reviewed by trained expert investigators. There is a possibility of ascertainment bias as we will depend on the clinicians caring for the patient to order the chest $\mathrm{x}$-ray and the arterial blood gas necessary to diagnose ALI. Fortunately, almost all patients requiring respiratory support do have these tests performed routinely every day. It is therefore extremely unlikely that a significant ALI would occur without the need to perform the chest $\mathrm{x}$-ray and the arterial blood gas as a part of clinical care.

Additional limitations of our approach come from the observational design of this study. First, because participants are not randomly assigned to the exposures under investigation, our study is particularly prone to indication bias, in that patients receiving certain therapies may be systematically different from those not receiving the therapies. If these differences are associated with the outcome of interest, the study results may be biased. Large sample size and a comprehensive collection of exposure variables will mitigate the potential bias by enabling our statisticians to adjust for any measured factor found to predict the use of each exposure under investigation. However, some important factors may be unknown or unmeasured, resulting in residual confounding and bias. The population based sample is clearly a strong point of our study. However, all patients will be treated in the two hospitals of the single teaching medical center, and, although internal validity will be high, the study results may not generalize to patients in other settings. Moreover, we will not be able to take advantage of additional variability in practice such as would be possible in multicenter studies involving different parts of the world. Long study period raises another question about whether the exposures, prognosis, and incidence of ALI will be stable enough to allow the proposed investigation. Fast pace changes in health care delivery and quality improvement initiatives could plausibly lead to the change in frequency of some of the proposed in-hospital exposures. Should changes in practice occur during the study period, our detailed observation of both practice and outcomes will give us an opportunity to correlate changes in practice with the development and outcome of ALI and possibly be able to make stronger causal inferences from the observed associations.

This causal translational research study will not affect the outcome of studied patients (this is a non-intervention epidemiologic study) but will help in better understanding the clinical pathogenesis of ALI and the design of future ALI prevention strategies. Since the therapeutic options are limited once ALI develops, the prevention is paramount. Unfortunately, effective prevention interventions do not currently exist, and our knowledge about clinical pathogenesis of ALI is limited. By identifying patients at high risk earlier (in the emergency department and operating room), and collecting biospecimens and clinical data before ICU admission we hope to improve our understanding of ALI and identify targets for future quality improvement interventions and ALI prevention trials. Previous studies have concentrated on patients in the ICU with already established ALI. Hence the inferences from these studies with regards to ALI pathogenesis and potential prevention targets are limited.

Potential future prevention strategies include, but are not limited to 1) quality improvement interventions to limit specific hospital acquired exposures (delayed treatment of infection and shock, aspiration triggers, high tidal volume ventilation, plasma transfusion from alloimmunized donors), and 2) the use of systemic and inhaled anticoagulants, antiplatelet agents, anti-inflammatory drugs and antioxidants. Some of these therapies have already been tested in preliminary clinical trials with encouraging result. This is in contrast to uniformly negative results of mechanistic interventions when applied later in the course of illness, once ALI is established.

\section{Conclusion}

This population based observational cohort study will define 1) the population of patients at high risk for ALI at the time of hospital admission 2) the most significant second hit in-hospital exposures that may modify the development and progression of ALI and 3) attributable burden of ALI in the community. The results will inform future mechanistic studies and clinical trials with an ultimate goal of preventing this devastating complication of critical illness.

\section{Acknowledgements}

The authors acknowledge Guangxi Li and Vitaly Herasevich for technical help with ICU Datamart. This research is supported by Mayo Foundation. 


\section{Authors' contributions}

All authors made substantial contribution to the study design and methods. SJT, LT, AA and MKR drafted the manuscript and all other authors critically revised it for important intellectual content. MMM, JAS and OG performed the statistical analysis. OG, RC and CT conceived the study, and participated in its design and coordination. All authors read and approved the final manuscript.

\section{Competing interests}

The authors declare that they have no competing interests.

Received: 3 July 2009 Accepted: 27 April 2010 Published: 27 April 2010

\section{References}

1. Avecillas J, Freire A, Arroliga A: Clinical epidemiology of acute lung injury and acute respiratory distress syndrome: incidence, diagnosis, and outcomes. Clin Chest Med 2006, 27(4):549-557.

2. Wiedemann HP, Wheeler AP, Bernard GR, Thompson BT, Hayden D, DeBoisblanc B, Connors AF Jr, Hite RD, Harabin AL: Comparison of two fluid-management strategies in acute lung injury. New England Journal of Medicine 2006, 354:2564-2575.

3. Ventilation with lower tidal volumes as compared with traditional tidal volumes for acute lung injury and the acute respiratory distress syndrome. The Acute Respiratory Distress Syndrome Network. N Engl J Med 2000, 342(18):1301-1308,

4. Matthay MA, Zimmerman GA, Esmon C, Bhattacharya J, Coller B, Doerschuk CM, Floros J, Gimbrone MA Jr, Hoffman E, Hubmayr RD, et al: Future research directions in acute lung injury: summary of a National Heart, Lung, and Blood Institute working group. Am J Respir Crit Care Med 2003, 167(7):1027-1035.

5. Gajic O, Dara S, Mendez J, Adesanya A, Festic E, Caples S, Rana R, St Sauver J, Lymp J, Afessa B, et al: Ventilator-associated lung injury in patients without acute lung injury at the onset of mechanical ventilation. Crit Care Med 2004, 32(9):1817-1824

6. Rana R, Fernandez-Perez ER, Khan SA, Rana S, Winters JL, Lesnick TG, Moore SB, Gajic O: Transfusion-related acute lung injury and pulmonary edema in critically ill patients: a retrospective study. Transfusion 2006, 46(9):1478-1483.

7. Khan H, Belsher J, Yilmaz M, Afessa B, Winters JL, Moore SB, Hubmayr RD, Gajic O: Fresh-Frozen Plasma and Platelet Transfusions Are Associated With Development of Acute Lung Injury in Critically III Medical Patients. Chest 2007, 131(5):1308-1314.

8. Gajic O, Rana R, Winters JL, Yilmaz M, Mendez JL, Rickman OB, O'Byrne MM, Evenson LK, Malinchoc M, DeGoey SR, et al: Transfusion-related acute lung injury in the critically ill: prospective nested case-control study. Am J Respir Crit Care Med 2007, 176(9):886-891.

9. Fernandez-Perez ER, Sprung J, Afessa B, Warner DO, Vachon CM, Schroeder DR, Brown DR, Hubmayr RD, Gajic O: Intraoperative ventilator settings and acute lung injury after elective surgery: a nested case control study. Thorax 2009, 64(2):121-127.

10. Shari G, Cartin-Ceba R, Trillo Alvarez C, Li G, Kashyap R, Kojicic M, Dong Y, Poulose JT, Herasevich V, Cabello Garza JA, et al: Timing to the Onset of Acute Respiratory Distress Syndrome in a Population Based Sample. Am J Respir Crit Care Med 2009, 179(1_MeetingAbstracts):A5099.

11. Iscimen R, Cartin-Ceba R, Yilmaz M, Khan H, Hubmayr RD, Afessa B, Gajic O: Risk factors for the development of acute lung injury in patients with septic shock: an observational cohort study. Crit Care Med 2008, 36(5):1518-1522.

12. Ferguson ND, Frutos-Vivar F, Esteban A, Gordo F, Honrubia T, Penuelas $\mathrm{O}$, Algora A, Garcia G, Bustos A, Rodriguez I: Clinical risk conditions for acute lung injury in the intensive care unit and hospital ward: a prospective observational study. Crit Care 2007, 11(5):R96.

13. Hudson LD, Milberg JA, Anardi D, Maunder RJ: Clinical risks for development of the acute respiratory distress syndrome. Am J Respir Crit Care Med 1995, 151(2 Pt 1):293-301.

14. Gong MN, Thompson BT, Williams P, Pothier L, Boyce PD, Christiani DC: Clinical predictors of and mortality in acute respiratory distress syndrome: potential role of red cell transfusion. Crit Care Med 2005, 33(6):1191-1198.

15. Fowler AA, Hamman RF, Good JT, Benson KN, Baird M, Eberle DJ, Petty TL, Hyers TM: Adult respiratory distress syndrome: risk with common predispositions. Ann Intern Med 1983, 98(5 Pt 1):593-597.
16. Ketoconazole for early treatment of acute lung injury and acute respiratory distress syndrome: a randomized controlled trial. The ARDS Network. Jama 2000, 283(15):1995-2002.

17. Jepsen $S$, Herlevsen $P$, Knudsen P: Antioxidant treatment with $n$ acetylcyesteine during adult respiratory distress syndrome: a prospective randomized placebo controlled study. Crit Care Med 1992, 20:819-923.

18. Meade MO, Jacka MJ, Cook DJ, Dodek P, Griffith L, Guyatt GH: Survey of interventions for the prevention and treatment of acute respiratory distress syndrome. Crit Care Med 2004, 32(4):946-954.

19. Wiedemann HP, Arroliga AC, Komara J, Denver VA, Welsh C, Fulkerson WJ $J$ r, MacIntyre N, Mallatratt L, Sebastian M, Sladen R, et al: Randomized, placebo-controlled trial of lisofylline for early treatment of acute lung injury and acute respiratory distress syndrome. Critical Care Medicine 2002, 30:1-6

20. Herasevich V, Yilmaz M, Khan H, Hubmayr RD, Gajic O: Validation of an electronic surveillance system for acute lung injury. Intensive Care Med 2009, 35(6):1018-1023.

21. Bernard GR, Artigas A, Brigham KL, Carlet J, Falke K, Hudson L, Lamy M, Legall JR, Morris A, Spragg R: The American-European Consensus Conference on ARDS. Definitions, mechanisms, relevant outcomes, and clinical trial coordination. Am J Respir Crit Care Med 1994, 149(3 Pt 1):818-824.

22. Cartin-Ceba R, Trillo Alvarez C, Li G, Kashyap R, Kojicic M, Dong Y, Poulose JT, Herasevich V, Cabello Garza JA, Shari G, et al: Derivation of a Lung Injury Prediction Score (LIPS) To Identify Patients at High Risk of ARDS at the Time of Hospital Admission. Am J Respir Crit Care Med 2009, 179(1_MeetingAbstracts):A4653.

23. Seferian E, Afessa B, Gajic O, Peters SG, Hubmayr RD, Keegan MT: Is there referral bias in the critically ill? Crit Care Med 2006, 43(12 Suppl):A19.

24. Calandra T, Cohen J: The international sepsis forum consensus conference on definitions of infection in the intensive care unit. Crit Care Med 2005, 33(7):1538-1548.

25. American College of Chest Physicians/Society of Critical Care Medicine Consensus Conference: definitions for sepsis and organ failure and guidelines for the use of innovative therapies in sepsis. Crit Care Med 1992, 20(6):864-874.

26. Banks PA: Practice guidelines in acute pancreatitis. Am J Gastroenterol 1997, 92(3):377-386.

27. Marik PE: Aspiration pneumonitis and aspiration pneumonia. N Engl J Med 2001, 344(9):665-671.

28. Derdak S: Acute respiratory distress syndrome in trauma patients. $J$ Trauma 2007, 62(6 Suppl):S58.

29. Arozullah AM, Daley J, Henderson WG, Khuri SF: Multifactorial risk index for predicting postoperative respiratory failure in men after major noncardiac surgery. The National Veterans Administration Surgical Quality Improvement Program. Ann Surg 2000, 232(2):242-253.

30. Arozullah AM, Khuri SF, Henderson WG, Daley J: Development and validation of a multifactorial risk index for predicting postoperative pneumonia after major noncardiac surgery. Annals of internal medicine 2001, 135(10):847-857.

31. Moss M, Bucher B, Moore FA, Moore EE, Parsons PE: The role of chronic alcohol abuse in the development of acute respiratory distress syndrome in adults. Jama 1996, 275(1):50-54.

32. Selzer ML: The Michigan alcoholism screening test: the quest for a new diagnostic instrument. Am J Psychiatry 1971, 127(12):1653-1658.

33. Moss M, Guidot DM, Steinberg KP, Duhon GF, Treece P, Wolken R, Hudson LD, Parsons PE: Diabetic patients have a decreased incidence of acute respiratory distress syndrome. Crit Care Med 2000, 28(7):2187-2192.

34. American Thoracic Society/European Respiratory Society International Multidisciplinary Consensus Classification of the Idiopathic Interstitial Pneumonias. This joint statement of the American Thoracic Society (ATS), and the European Respiratory Society (ERS) was adopted by the ATS board of directors, June 2001 and by the ERS Executive Committee, June 2001. Am J Respir Crit Care Med 2002, 165(2):277-304.

\section{Pre-publication history}

The pre-publication history for this paper can be accessed here: http://www.biomedcentral.com/1471-227X/10/8/prepub

doi:10.1186/1471-227X-10-8

Cite this article as: Thakur et al: Towards the prevention of acute lung injury: a population based cohort study protocol. BMC Emergency Medicine 2010 10:8. 